\title{
BREASTFEEDING TEMPORAL DISTRIBUTION TRENDS AMONG NEONATES IN TERTIARY CARE HOSPITAL IN LAHORE
}

Hamid Mahmooda, Zarmast Khan ${ }^{b}$, Abdul Raufc, Ammara Waqar ${ }^{d}$

aStudent University Institute of Public Health, University of Lahore, Lahore.

${ }^{b}$ Associate Professor Shifa Shaheed-e-Millat University, Islamabad.

'Assistant Professor Al-Aleem Medical College, Lahore.

${ }^{\mathrm{d} D i r e c t o r}$, QEC, Al-Aleem Medical College, Lahore.

\section{ABSTRACT:}

BACKGROUND \& OBJECTIVE: Breastfeeding provides immunity against bacterial, viral, and other infectious diseases. More than four million new neonates die due to vaccine-related diseases in the first 28 days of their lives. It is therefore emphasized that breastfeeding in the first hours after delivery may save the neonate. The objective of this study was to determine the factors affecting the pattern of breastfeeding among the neonates and assess the frequency of early breastfeeding among neonates at Gulab Devi Hospital, Lahore.

METHODOLOGY: It was a cross-sectional descriptive study. One hundred mothers were selected through convenient purposes sampling. Chi-square test applied for an association between mode of delivery and initiation of breastfeeding.

RESULTS: The result of the study showed variability in the time of breastfeeding by the mothers from one hour to 24 hours after delivery.Pre-lacteal was given to 59 mothers, while 41 were not given with any pre-lacteal. A significant association was found between mode of delivery and initiation of breastfeeding with a $p<0.001$.

CONCLUSION: The result of the study showed that variability in the time of breastfeeding by the mothers from one hour to 24 hours after delivery provided a significant difference in the production of the neonate in the first 28 days.

KEYWORDS: Breastfeeding, WHO Criteria, Immunity, Temporal patterns.

doi: https://doi.org/10.37723/jumdc.v12i2.538

\section{How to cite this:}

Mahmood $\mathrm{H}$, Khan Z, Rauf A, Waqar A. BREASTFEEDING TEMPORAL DISTRIBUTION TRENDS AMONG NEONATES IN TERTIARY CARE HOSPITAL IN LAHORE. jumdc. 2021;12(2):126-132.

doi: https://doi.org/10.37723/jumdc.v12i2.538

This is an Open Access article distributed under the terms of the Creative Commons Attribution License (http://creativecommons.org/licenses/by/4.0), which permits unrestricted use, distribution, and reproduction in any medium provided the original work is properly cited. 


\section{INTRODUCTION:}

Breast milk is known to be a blessing of Allah. It provides complete nutrition for the protection of neonates in the early hours of his life. It provides immunity against bacterial, viral, and other infectious diseases. More than four million neonates die due to vaccine-related diseases in the first 28 days of their lives ${ }^{[1]}$. WHO has provided guidelines regarding protecting, promoting, and supporting breastfeeding facilities thus providingmaternal and newborn services ${ }^{[2]}$. Breastfeeding is getting attention worldwide, according to WHO surveys ${ }^{[3]}$. There are more than 132 million babies born every year. Out of these babies, 121 million are breastfed, but they are not fulfilling the criteria of the WHO to be fed within the first hour after their birth ${ }^{[4]}$.

This adds to themagnitudeof the problem in a developing country like Pakistan, where the infant mortality rate is already about 72 per 1000 live birth.

According to the economic survey of Pakistan 2004-05, breastfeeding was recorded to be very low in Pakistan. ${ }^{[5]}$ The Infant Mortality Rate (IMR) has shown to be very high at 72 deaths per 1000 live births. According to the survey conducted by the IBFAN Asia Pacific's World Breastfeeding Trends initiative (WBT), which has placed Pakistan in the " $C$ " category scoring 74.5 out of 150 and has been ranked 3rd in the SARRAC countries [6]. Neonate Mortality Rate (NMR) is very high in South Asia, accounting for $51 \%$ of all the under 5 years of death. The IMR is strikingly low in Africa which is about $33 \%$, contributing to only $39 \%$ of the neonate deaths. Diarrhea is considered to be one of the leading causes of death in newborn ${ }^{[7]}$. Considering the protective role of breastfeeding against diarrhea, it is emphasized that breastfeeding in the first hours after delivery may reduce the neonatal mortality. Breastfeeding is considered to be the first food for the neonate ${ }^{[8,9]}$.

It provides nutrition as well as defense against foreign bodies. Keeping in view the significance of breastfeeding, we conducted this study to find the pattern of breastfeeding in newborns. No such study has previously been carried out in Pakistan ${ }^{[10,11]}$. Hence, this study will help us finding out the factors affecting/influencing initiation of exclusive breastfeeding among the neonates of mothers delivered, and assess the frequency of early breastfeeding among neonates at Gulab Devi Hospital, Lahore.

Corresponding Author:

Dr. Hamid Mahmood

Student University Institute of Public Health, University of Lahore, Lahore. Email: drhamidmahmood373@gmail.com

\section{METHODOLOGY:}

It was a cross-sectional descriptive study conducted among neonates of mothers delivered at Gulab Devi Hospital, Lahore, for 6 months duration(September 2018 to February 2019). The sample size of this study was calculated using a sample size calculator website open EPI(https:// www.openepi.com/SampleSize/SSCohort.htm) and one hundred mothers were selected through convenient purpose sampling. Information was collected regarding their breastfeeding initiation in the few hours after delivery. Informed written consent was take from mother.

Data was collected from willing mothers who delivered their babies. Out of the normally delivered women, Every 5thmother was selected without any complication to make the study more reliable. The interview of the mothers was conducted in thelocal language according to the education and cultural norms. Verbal consent was also taken before the interview. The following mother's will be included in the study whose babies are less than 1 month, those who can do breastfeeding to their babies and excluded whose babies are greater than 1 month, they can't do breastfeeding to their babies, and those who birth twins babies.

Data was collected and analyzed on SPSS version 24. Breastfeeding practices are noted in frequency and percentage, and a chi-square test is applied for an association between mode of delivery and initiation of breastfeeding. 


\section{RESULTS:}

The result of the study showed variability in the time of breastfeeding by the mothers from one hour to 24 hours after delivery. Twenty-two mothers were breastfeeding to their infants within 1 hour after delivery, 31 mothers breastfeeding 1-6 hours, 35 women breastfeeding after 7-12 hours, and the remaining 12 women breastfeeding 13-24 hours after delivery (Table-I).

Regarding the mode of deliveries, 21 mothers delivered through Spontaneous Vaginal Delivery (SVD) started breastfeeding their neonates within6 hours. The mothers who delivered via Lower Segment Caesarean Section (LSCS) started breastfeeding after 6-12 hours. The difference has been considered significantly important according to the mode of delivery and start of breastfeeding. Ninety six infants were fed with colostrum while pre-lacteal was given to 59 infants(Figure:I-II).

A significant association was found between mode of delivery and initiation of breastfeeding with a $\mathrm{p}<0.001$ (Table-II).

Table-I:Frequency Distribution in Relation to Breastfeeding Practices of Present Pregnancy.

\begin{tabular}{|c|c|}
\hline Breastfeeding Practices & N (\%) \\
\hline Time initiation Breastfeeding (Hours) & $22(22 \%)$ \\
\hline Within one hour & $31(31 \%)$ \\
\hline 1 to 6hours & $35(35 \%)$ \\
\hline 7 to 12 hours & $12(12 \%)$ \\
\hline 13 to 24 hours & $\mathbf{1 0 0}$ \\
\hline Total & \\
\hline
\end{tabular}

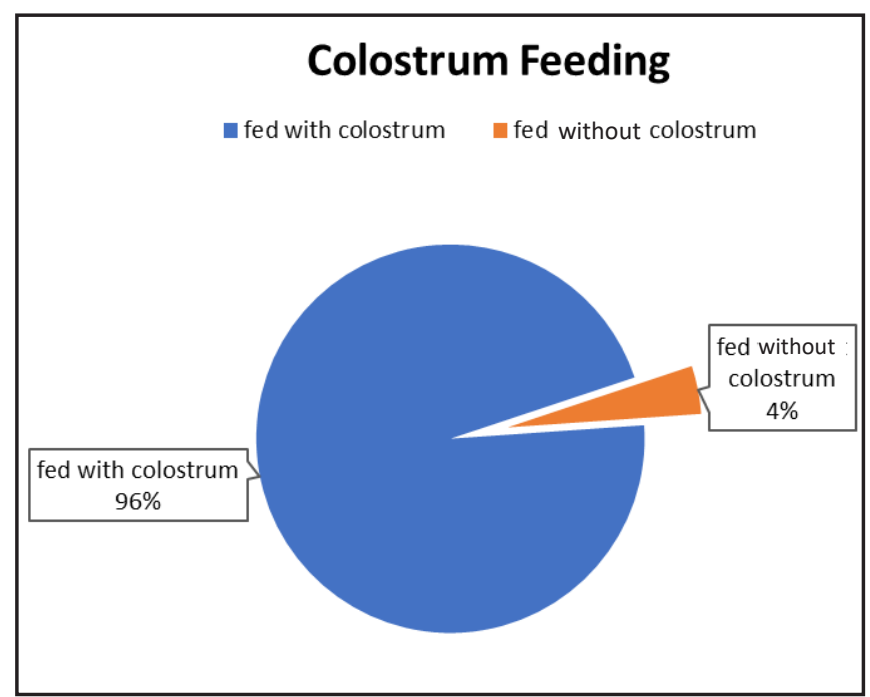

Figure-I: Colostrum feeding.

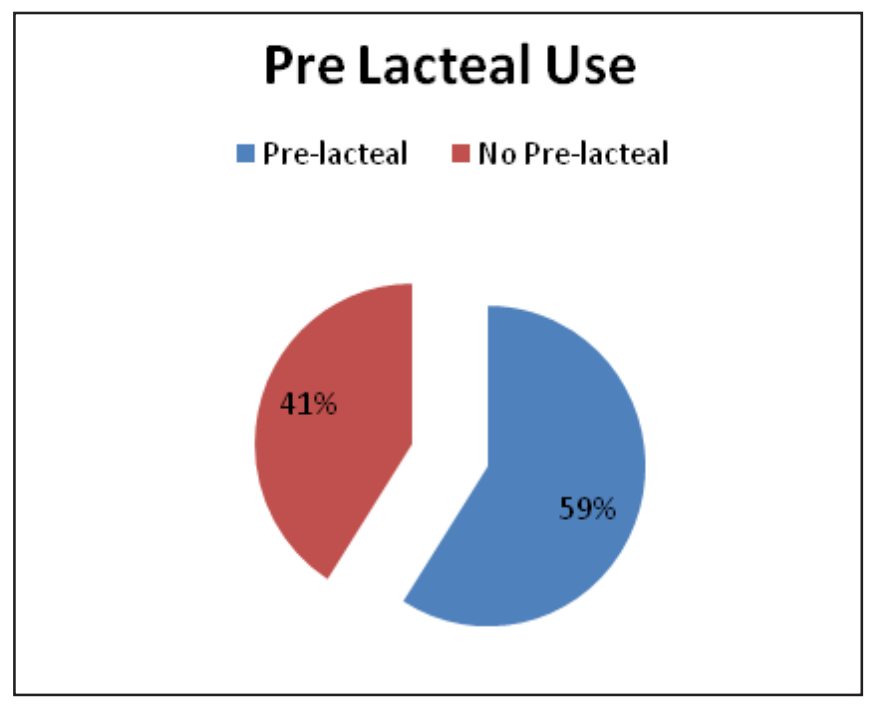

Figure-II:Used of prelacteal. 
Table-II: Association between Mode of Delivery and Initiation of Breastfeeding.

\begin{tabular}{|c|c|c|c|c|}
\hline \multirow{2}{*}{ Mode of Delivery } & \multicolumn{2}{|c|}{ Initiation Breastfeeding } & \multirow{2}{*}{ p-value } \\
\cline { 2 - 4 } & $\mathbf{>} \mathbf{6}$ Hours & $\leq \mathbf{6}$ Hours & Total & \\
\hline Spontaneous Vaginal Delivery & 28 & 51 & 79 & \multirow{2}{*}{$<0.001$} \\
\hline Lower Segment Caesarean Segment & 19 & 2 & 21 & \\
\hline Total & $\mathbf{4 7}$ & $\mathbf{5 3}$ & $\mathbf{1 0 0}$ & \\
\hline
\end{tabular}

\section{DISCUSSION:}

Breastfeeding is considered as an emotional bond between motherand child that is important for emotional, psychological, and physical growth of the child. The mother is considered to be one of the best immunity providers to neonates. Breast milk is full of immunoglobulin, which provides defense against viruses and bacteria in the neonatal period. The importance of breast milk is well established. The study has been carried out on the mothers with normal delivery and LSCS who started delayed breastfeeding, increasing neonatal mortality ${ }^{[12]}$.

Early initiation of breastfeeding has been recommended by the $\mathrm{WHO}^{[13]}$. The $\mathrm{WHO}$ has recommended breastfeeding the first as it provides the babies the immunological effect of colostrum (first breast milk) which provides protection to the babies against disease and infection. The WHO has recommended exclusive breastfeeding during the first 6 months of babies life, which can continue along with additional tools upto 2 years or beyond. The first hour after birth is called a golden hour because it is the transition of newborn babies from internal to an external environment ${ }^{[14]}$.

The Lancet Breastfeeding Series Group carried out a study on epidemiology, mechanisms, and lifelong effects of breastfeeding in the 21st century: They found out the early initiation of breastfeeding played an important in the development and growth of newborn babies. It also provided information regarding the immunological protective mechanism in newborn babies ${ }^{[15]}$.

A research regarding Prevalence of and factors associated with early initiation of breastfeeding among women with children aged < 24 months in Kilimanjaro region, northern Tanzania. This was a community-based cross-sectional study. The result of the study showed that the early initiation of breastfeeding increased the development and growth of newborn babies, which is in line with our present study ${ }^{[16]}$.To determine the determinants of early initiation of breastfeeding among Mothers in Northwestern Romania and Saudi Arabia.The early initiation has increased the immunological protection in the newborn babies, which is consistent and produces astonishing good results by decreasing the morbidity and mortality in the newborn baby ${ }^{[17,18]}$.

WHO has defined criteria for early initiation of breastfeeding to promote exclusive breastfeeding in 2019. The WHO has emphasized the initiation of early breastfeed due to the good nutrition values of breastfeeding, which is necessary for babies' development and growth ${ }^{[19]}$.

Checked the effects on neonatal mortality and Morbidity through systematic review and meta-analysisandfinding was out that the early initiation in breastfeed has reduced the newborn mortality to a great extent ${ }^{[20]}$ and the delayed breastfeeding by the mothers can badly affect on the health of newborn babies [21].

The Moderating effect of urban versus rural residence on the relationship between type of birth attendant and early initiation of breastfeeding in Ghana ${ }^{[22]}$ concluded that the role of birth attendant is very important in the early initiation of breastfeeding, almost the same as the role of healthcare provider and the birth attendant in educating the mother for initiation of the breastfeeding of the first hour is directly related 
to the educational, moral and health literacy of the birth attendants and Bangladesh ${ }^{[23]}$ the mothers having normal virginal delivery started breastfeeding within one hour as compared to women who were having C-section.

In our study, the mode of delivery of the baby was considered as a positive associated factor. Different studies have been carried out where skilled, educated, and trained birth attendants have started educating the mothers for breastfeeding as early as possible as proved to be an important factor for the success of the early breastfeeding program.

During the study, it has been observed that the breastfeeding practiced in Pakistan is due to overcrowding of the patients in the Gynecology Department where the trained / skilled workers are lacking. Improvement can only be made if the provision of educated/trained healthcare workers can guide the mothers about the importance of early breastfeeding and the hazards of delayed breastfeeding.

The results of this study are significant to find the gaps between the criteria described by the WHO for the starting of breastfeeding to neonates by the mothers and the practices carried out in the hospitals, clinics, and homes by the mothers. It will be worth mentioning here that the conditions can only be improved if the mother ought to be educated by skilled, educated, and trained healthcare workers and doctors about the importance of early breastfeeding by the mothers. Development of baby-friendly hospitals and clinics that can educate mother and their families regarding the importance of healthcare should be encouraged. Female community health workers should be encouraged to motivate the mothers regarding breastfeeding.

Different proposals were brought under discussion for the encouragement of mothers regarding early breastfeeding by mothers. The health workers need a multi-level approach to start breastfeeding within 1 hour after delivery. A campaign should be started by the public-private sector, hospitals, and clinics to promote early breastfeeding by the mothers. The environment of community workers regarding the education, support, and guidance of the women who are going to become a mother should be done on a war footing. Educational promotion should be started among college and university students.

\section{CONCLUSION:}

The result of the study showed that variability in the time of breastfeeding by the mothers from one hour to 24 hours after delivery. It has been observed that the criteria set by WHO has been followed by the urban mothers who have been educated by the healthcare workers to initiate early breastfeeding in the first hour after delivery. It is, therefore, the need the time that awareness/education about the importance of initiation of breastfeeding in the first hour after delivery must be created among the community.

\section{FURTHER RECOMMENDATIONS:}

Breastfeeding is one of the most important elements in the promotion of mother and child health. Only a limited number of factors affecting breastfeeding have been studied so far. It is therefore recommended that more detailed studies having different variables must be included to make a wider policy about the early breastfeeding in the mothers be promoted.

ACKNOWLEDGEMENT: None.

CONFLICT OF INTEREST: All authors disclose no conflict of interest.

\section{GRANT SUPPORT \& FINANCIAL DISCLOSURE: None}

\section{REFERENCES:}

1. World Health Organization. Guideline: protecting, promoting and supporting breastfeeding in facilities providing maternity and newborn services. World Health Organization; 2017.

2. Takahashi K, Ganchimeg T, Ota E, Vogel JP, Souza JP, Laopaiboon M, et al. Prevalence of early initiation of breastfeeding and determinants of delayed initiation of breastfeeding: secondary analysis of the WHO global survey. Scientific Reports. 2017;7:44868. Doi: 10.1038/srep44868. 
3. Hepper PG. The developmental origins of laterality: Fetal handedness. Developmental Psychobiology. 2013;55(6):588-595. Doi: 10.1002/dev.21119.

4. World Health Organization. Ghana Health Service and its Health Partners engage the media during Breastfeeding Week; 2018 August 08 [cited 2019 Dec 12]. Availablefrom: [https://www.afro.who.int/news/ghanahealth-service-and-its-health-partnersengage-media-during-breastfeeding-week].

5. Bhandari S, Thorne-Lyman AL, Shrestha B, Neupane S, NonyaneBA, Manohar S, et al. Determinants of infant breastfeeding practices in Nepal: A national study. International Breastfeeding Journal. 2019;14(1):14. Doi: 10.1186/s13006-019-0208-y

6. Victora CG, Bahl R, Barros AJ, França GV, Horton S, Krasevec J, et al. Breastfeeding in the 21st century: epidemiology, mechanisms, and lifelong effect. The Lancet. 2016;387(10017):475-490. Doi: 10.1016/ S0140-6736(15)01024-7.

7. Asim M, Nawaz Y. Child malnutrition in Pakistan: evidence from literature. Children. 2018;5(5):60. Doi:10.3390/ children 5050060

8. Herba CM, Roza S, GovaertP, Hofman A, Jaddoe $V$, Verhulst FC, et al. Breastfeeding and early brain development: the Generation R study. Maternal \& Child Nutrition. 2013;9(3):332349.Doi: $10.1111 / \mathrm{mcn} .12015$.

9. Asare BY, Preko JV, Baafi D, Dwumfour-Asare $B$. Breastfeeding practices and determinants of exclusive breastfeeding in a cross-sectional study at a child welfare clinic in TemaManhean, Ghana. International Breastfeeding Journal. 2018;13(1):12. Doi:10.1186/s13006-0180156-y

10. Coomson JB, Aryeetey R. Perception and practice of breastfeeding in public in an urban community in Accra, Ghana. International Breastfeeding Journal. 2018;13(1):18. Doi:10.1186/s13006-018-0161-1

11. Yang, S, Martin RM, Oken E, Hameza M, Doniger G, Amit $S$, et al. Breastfeeding during infancy and neurocognitive function in adolescence: 16-year follow-up of the PROBIT cluster-randomized trial. PLOS Medicine.2018:15(4): e1002554. Doi: 10.1371/journal.pmed.1002554.
12. Johnston DW, Nicholls ME, Shah M, Shields MA. Handedness, health and cognitive development: evidence from children in the National Longitudinal Survey of Youth. Journal of the Royal Statistical Society: Series A (Statistics in Society). 2013;176(4):841-860. Doi: 10.1111/j.1467-985X.2012.01074.x.

13. Girard LC, Doyle O, Tremblay RE. Breastfeeding, cognitive and noncognitive development in early childhood: a population study. Pediatrics. 2017;139(4):e20161848. Doi: $10.1542 /$ peds.2016-1848.

14. Bortz K. WHO, UNICEF: 78 million newborns not breastfed within first hour after birth. Infectious Diseases in Children. 2018;31(9):19-19.

15. Sharma D. Golden hour of neonatal life: Need of the hour. Maternal Health, Neonatology and Perinatology. 2017;3(1):16. Doi:10.1186/ s40748-017-0057-x

16. Ali F, Mgongo M, Mamseri R, George JM, Mboya IB, Msuya SE. Prevalence of and factors associated with early initiation of breastfeeding among women with children aged < 24 months in Kilimanjaro region, northern Tanzania: a community-based crosssectional study. International Breastfeed Journal. 2020;15(1):80. Doi: 10.1186/ s13006-020-00322-8.

17. Cozma-Petruţ A, Badiu-Tişa I, Stanciu O, Filip L, Banc R, Gavrilaş L, et al. Determinants of Early Initiation of Breastfeeding among Mothers of Children Aged Less than 24 Months in Northwestern Romania. Nutrients. 2019;11(12):2988. Doi: 10.3390/ nu11122988.PMID: 31817702

18. Ahmed AE, Salih OA. Determinants of the early initiation of breastfeeding in the Kingdom of Saudi Arabia. International Breastfeeding Journal. 2019;14(1):13. Doi: 10.1186/s13006-019-0207-z

19. World Health Oganization. Early initiation of breast feeding to promote exclusive breastfeeding; 2019Feb 11 [Cited 2020]. Availablefrom :http://www.who.int/elena/ titles/early_breastfeeding/en/

20. Khan J, Vesel L, Bahl R, Martines JC. Timing of breastfeeding initiation and exclusivity of breastfeeding during the first month of life: effects on neonatal mortality and morbidity-A systematic review and meta- 
analysis. Maternal and Child Health Journal. 2015;19(3):468-479.Doi: 10.1007/s10995014-1526-8

21. Takahashi K, Ganchimeg T, Ota E, Vogel JP, Souza JP, Laopaiboon $M$, et al. Prevalence of early initiation of breastfeeding and determinants of delayed initiation of breastfeeding: secondary analysis of the WHO Global Survey. Scientific Reports. 2017;7:44868. Doi: 10.1038/srep44868

22. Haile ZT, Sarfo B, Francescon J, Chertok IR, Teweldeberhan AK, Chavan B. The Moderating effect of urban versus rural residence on the relationship between type of birth attendant and early initiation of breastfeeding in Ghana. Journal of Human Lactation. 2018;34(4):810820.Doi: $10.1177 / 0890334417741881$

23. Karim F, Billah SM, Chowdhury MA, Zaka $\mathrm{N}$, Manu $\mathrm{A}$, Arifeen $\mathrm{SE}$, et al. Initiation of breastfeeding within one hour of birth and its determinants among normal vaginal deliveries at primary and secondary health facilities in Bangladesh: a case-observation study. PloS one. 2018;13(8):e0202508. Doi:10.1371/journal.pone.0202508

\section{Authors contribution:}

Hamid Mahmood: Study design, and drafting. Zarmast Khan: Correction and revision. Abdul Rauf: Data analysis, result compilation Ammara Waqar: Biostatistics, result compilation.

Submitted for Publication:12-06-2017 Accepted after revision: 09-04-2021 